\title{
Extended Modal Realism - a New Solution to the Problem of Intentional Inexistence
}

\section{Andrew D. Thomas ${ }^{1}$}

Received: 16 April 2019 / Revised: 5 August 2019 / Accepted: 3 September 2019 / Published online: 8 November 2019

(C) The Author(s) 2019

\begin{abstract}
Kriegel described the problem of intentional inexistence as one of the 'perennial problems of philosophy' (Kriegel Philosophical Perspectives 21(1), 307-340, 2007: 307). In the same paper, Kriegel alluded to a modal realist solution to the problem of intentional inexistence. However, Kriegel does not state by name who defends the kind of modal realist solution he has in mind. Kriegel also points out that even what he believes to be the strongest version of modal realism does not pass the 'principle of representation' and thus modal realism is not an adequate solution to the problem of intentional inexistence. In this paper, I respond to Kriegel by defending a modal realist solution that he did not consider in 2007, called 'extended modal realism' (EMR). EMR is a version of modal realism where possible worlds are not completely isolated as they are under the Lewisian model. Rather, under EMR worlds are, in a way, spatiotemporally related. The fact EMR worlds are related allows EMR to sufficiently pass the principle of representation and thus can be deemed a legitimate solution to the problem of intentional inexistence. I conclude that either EMR can pass the principle of representation in some cases or, and I think the more sensible option, we give up on the principle of representation altogether.
\end{abstract}

Keywords Intentionality · Extended modal realism - Intentional inexistence · Non-existence

Andrew D. Thomas

andrew.thomas@durham.ac.uk

1 Durham University, 50 Old Elvet, Durham, DH1 3HN, UK 


\section{Introduction}

The problem of intentional inexsistence was originally raised by Brentano (2012) and has notably been developed by Prior (1971) and Crane (2013). ${ }^{1}$ The concern is that, if intentionality is a relation between two objects then for a relation of this structure to hold it requires the existence of both its relata. The problem is essentially, 'How can we stand in an intentional relation with an object if that object does not exist?' Dummett states that 'intentionality is naturally taken to be a relation between the mental act, or its subject, to the object of that act'. Dummett continues by articulating the problem: 'how can there be a relation when the second term of the relation does not exist?' (Dummett 2014, 36).

There are four ways one can go to solve this puzzle. First is to deny that intentional acts towards non-existent objects are possible. Second, one could, like Prior challenge that intentionality is a relation. Crane developed this line of thought and challenged whether intentionality is always a relation. However, this move, made by Crane (2001) and Crane (2013), is a reaction to the problem of intentional inexistence and is seemingly not independently motivated. Thus, we might think it is the standard or common sense position to think of intentionality as a relation. Alternatively, Priest (2016: 58-59) favours the approach that we can stand in intentional relations with non-existent objects. Another option is to suggest that the objects of our intentions exist as parts of possible worlds. The view that there are real modalities other than the actual one is known as modal realism. Traditionally this view is attributed to Lewis (1986). However, Lewis's modal realism is not the only option available. Since Yagisawa (1988) a version of modal realism called extended modal realism (EMR) has been in development. Under EMR existence is a set theoretic notion. ${ }^{2}$ Modal realists such as Lewis think that there are non-actual concreta of which possibilia are a kind and we stand in intentional relations with such things. ${ }^{3,4}$ EMR succeeds with the problem of intentional inexistence where Lewis's modal realism

\footnotetext{
${ }^{1}$ Crane (2006) points out that there are some interpretive issues with how $20^{\text {th }}$ century philosophers have understood Brentano's use of the term 'intentional inexistence'. However, Kriegel uses the phrase 'intentional inexistence' and since this paper is a response to him I will use the same terminology. Whether or not Kriegel is aware of Crane's concern is not the purpose of this paper. It is clear that Kriegel at least wants to engage with what might properly be called the problem of non-existence or as Crane (2001: 22-23) calls it the problem of intentionality. The fact Kriegel rejects modal realism as a possible response to the problem he has in mind is evidence that he is thinking of something like the problem of non-existence or the problem of intentionality. Modal realism would be of no help to the problem of intentional inexistence if we had in mind Crane's reading of Brentano.

${ }^{2}$ Under EMR objects exist only if they bare the membership relation to a give set. See Yagisawa (2014) for Yagisawa's theory of existence.

${ }^{3}$ What exactly possibilia are depends on ones ontology. For Lewis (1986) they are parts of concrete possible worlds. Whereas Yagisawa remains non-committal on the concreteness of his worlds (Yagisawa 2010, 179: fn 7). However, it is still open as to whether the world-stages of objects are concrete or not. To do justice to different kinds of modal realism, when defending modal realism in this paper, I will use the term 'non-actual objects'. This term ranges over possibilia and impossilia remaining non-committal on their concreteness. The concreteness of worlds and world-stages is a point where EMR would benefit from some clarification and development.

${ }^{4}$ Although Kriegel's primary concern is with possibilia, I anticipate that the same criticisms made against possibilia would also be made against impossibilia.
} 
could not. EMR was introduced as an extension of the Lewisian project in Yagisawa (1988) and developed in Yagisawa (2010). Although it was not intended as an answer to this problem it works well. As far as I am aware Yagisawa has not yet formulated an explicit answer to the problem of intentional inexistence. However, it is clear he is aware of its usefulness from his comments (Yagisawa 2014, 14).

In this paper, I respond to Kriegel who dismisses modal realism as a solution to the problem of intentional inexistence on the grounds that even presented in its strongest form it does not meet the principle of representation (Kriegel 2007, 311). The modal realist would attempt to solve the problem of intentionality by suggesting that the objects of intention are not non-existent but rather exist as a part of a possible world. The principle of representation is that causal contact is a precondition for the possibility of representation (even if it is not constitutive of the representation itself). Under the most well-known form of modal realism, that of Lewis, possible worlds are spatiotemporally isolated wholes, and according to Kriegel the fact that Lewisian possible worlds are causally isolated renders modal realism insufficient to pass the principle of representation. However, EMR can respond to this problem.

The outline of this paper is as follows: in $\S 2$, I provide some comments on the nature of intentionality and its structure. Here I also motivate the problem of intentionality formulated as an inconsistent triad. In $\S 3$ I outline some responses to the problem of intentionality, then in $\S 4$, I provide Kriegel's description of modal realism and I highlight why Kriegel thinks modal realism fails. In $§ 5$, I provide a brand of modal realism (EMR) that Kriegel did not consider and show how it meets the principle of representation. I end with the disjunctive conclusion that either EMR passes the principle of representation or that the principle of representation should be rejected since it cannot be satisfied by many other theories. If the former is correct, then on Kriegel's grounds I have established a successful modal realist solution. If the latter is correct then we have reason to reject the principle of representation as a reasonable criterion by which to judge a response to the problem of intentional inexistence.

\section{Intentionality}

Kriegel gives us no definition of intentionality. However, since Kriegel wishes to establish intentionality as an adverbial property rather than a relation it would be helpful to have a grasp on the term in question. For Brentano intentionality characterised mental activity (Brentano 2012, 88). Berto elaborates and points out that Brentano might have been wrong by claiming that all mental states bear intentionality. However, most scholars agree that at least some mental states do (Berto 2018, 3). Crane (2013: 4) tells us that '...every intentional state or episode has an object - something it is about or directed on'. Yablo defines intentionality in terms of aboutness, 'the relation that meaningful items bear to whatever it is that they are on or of or that they address or concern' (Yablo 2014, 1). Sometimes intentionality is simply described in terms of directedness or aboutness (Mumford and Anjum 2011, 185). As I consider the problem of intentional inexistence I have in mind Mumford and Anjum's definition. I have elected to employ this definition since it is neutral on 
whether intentionality is a relation or not, and establishing whether intentionality is a relation or not is not the primary purpose of this paper.

Figure 1 outlines the standard structure of intentionality. Where we have an existing agent $a$ bearing an intentional act towards an existing object $x$. The direction of the intentional act $F$ is indicated by the arrow symbol.

\subsection{Intentionality and Representation}

Before I begin in full there is a quick aside, I should note that Kriegel is happy to switch the terms representational and intentionality. He states, "what all these have in common is that they involve intentionality or representation: they represent something' (Kriegel 2007, 308, (Kriegel's emphasis)). Kriegel also reorganises the problem of intentional inexistence replacing the obviously intentional term 'thinking of' with the less obviously intentional term 'represents' (Kriegel 2007, 308). It is not entirely clear what Kriegel aims to achieve by switching the terms 'representation' and 'intentionality'. It is Kriegel's project to establish that representation and intentionality are not relations and thus this general project might have something to do with the shift in terminology. It is undeniable that intentionality is a kind of representation. One could argue that Intention is a particular genus of the family of Representation. Priest states, 'The intentionality of mental states is one kind of representation. It is not the only kind' (Priest 2014, 160). Even if it is true that representation is not a relation this says nothing about intentionality. Unless Kriegel thinks what is true of the family is true of all its 'genera', which is plainly false. What is true of some Canidae is not necessarily true for all Caninae. For example, Caninae have distinguishing characteristics including small, simple, well-spaced premolars and a humerus without an entepicondylar foramen. The fact that Intentionality belongs to the family Representations does not mean Intentionality cannot have distinguishing features, such as being relational. If Kriegel thinks the terms are equivalent, then a switch is permissible. However, there is reason to think that the terms are not strictly equivalent and therefore a switch is not acceptable. My thinking about the lion is an intentional act that represents the lion. However, a map of Newcastle also represents Newcastle but the map's representation is not intentional in the same way that thinking about a lion is. Given the fact that there are some representations that are not intentional in the same way mental acts are the two terms cannot be switched salva veritate.

In order to do justice to both sides of this debate over whether intentionality and representation are relations, I will assume that intentionality and representation are equivalent. I use the letter ' $F$ ' to indicate the presence of intentionality or representation. Since if intentionality and representation are equivalent then using a neutral letter to indicate the presence of either term is fair. However, if the terms are not

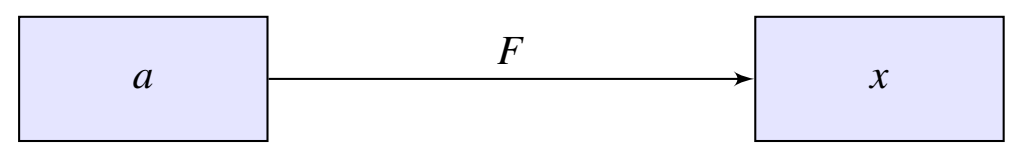

Fig. 1 The structure of intentionality 
equivalent and there is an objection to using a neutral letter to signify their presence, then Kriegel has made an argumentative misstep which needs to be addressed. The motivation for this might be that it seems less controversial for us to think of representation as non-relational than intentionality as a non-relational. Kriegel's argument rests on developing Chisholm's account of perception as a non-relational form of representation. Therefore, it is of obvious benefit to Kriegel if he can bring intentionality closer to the same kind of representation as Chisholm had in mind (Chisholm 1957).

With this aside out of the way I will return to the problem at hand.

\subsection{The Problem of Intentional Inexistence}

The problem of intentional inexistence can be broken-down into three propositions.

1. An agent $(a) F$ s something $(x)$ non-existent.

2. An agent $(a)$ cannot $F$ something $(x)$ non-existent if $F$ is a relation.

3. Fing something $(x)$ constitutively involves bearing a relation to it. ${ }^{5}$

The first statement seems obvious, you can think of a non-existent object even though that object is non-existent. For example, you can think of Pegasus, the future, a square circle, or other ways the world could have been even though these objects do not exist. $^{6}$

On the face of it, the second claim is also straightforward; it relies on the assumption discussed by Hawthorne and Manley that no relational expression can be about an object unless that object exists (Hawthorne and Manley 2012, 9).

The final claim is more controversial; it rests on the concept of intentionality as a relation. You might choose to get off the bus here and disagree over whether intentionality is a relation. However, for those who want to maintain the relational structure of intentionality the problem of intentional inexistence is one problem they must consider. The problem of intentional inexistence is: 'how can we represent something that doesn't exist, given that representation involves bearing a relation to

\footnotetext{
${ }^{5}$ The use of the term 'constitutively' is to follow Kriegel's convention. It is not a term I have introduced. Moreover, Kriegel's use of the term 'constitutively' is dubious. Kriegel takes 'constitutively' to mean that if the relation were not present then the intentional act would fail. However, it is extremely unclear how we are to understand Kriegel's short discussion of this point. Kriegel (2007: 312) states, 'Perhaps representation often involves a relation to the represented, but it never does so constitutively'. I am unsure what to make of this, after all there is a significant difference between the ways we could understand the use of the term 'often' here. It could be understood to mean that some intentional acts bear a relation to the object and others not. Or it could mean that at certain times representations are relational. There is, finally, how I think Kriegel wants us to interpret this statement which is: 'representational acts are a kind of which most are relational but the relational aspect is not the important feature of these acts'. It is not my purpose in this paper to discuss in too much detail how Kriegel sets up the problem but rather to respond to how he dismisses one viable option to the problem. However, what exactly the problem with the 'problem of intentional inexistence' is does need clarification, but that will be a topic for another paper.

${ }^{6}$ Under the metaphysics I offer some of these objects do exist but for the sake of setting up the problem, let's say they do not. Furthermore, some philosophers might try to tell me I cannot represent impossible things such as square circles or positively charged electrons. In response, I can provide two cases where this feat is achievable, see Priest (1997) and Priest (1999). You do not need to conjure up a minds-eye picture to successfully represent something.
} 
it and we cannot bear a relation to something that doesn't exist' Kriegel (2007: 307).

The problem arises when there is an existing agent standing in an intentional relation with a non-existent object. The indeterminate nature of non-existent objects prompts the question, 'What is in the object box?'

\section{Responses}

There are a number of responses which Kriegel deems to be unsuccessful. Before I reach the one I would like to defend I will sketch two others namely the 'abstracta' and 'mental concreta' views, which are two forms of the same idea. The idea behind both of these responses is that when we are thinking of non-existent objects we are thinking about something. In the first form our intentional act is about existent abstracta and in the second form of the idea our intentional act is about mental concreta. When you think of Sherlock Holmes you are thinking about something which exists, but only an "abstract entity that "lives" altogether outside space-time or of a mental object that "lives" only in your mind" (Kriegel 2007, 310).

Kriegel dismisses both these options on the charge of 'familiar intuitive, ontological, epistemological, and phenomenological difficulties' (Kriegel 2007, 310).

1. Intuitively, Bigfoot seems to be a non-mental concretum, though one that does not exist, rather than an existing abstractum or mental concretum.

2. Ontologically, commitment to abstracta and mental concreta is a liability that we should not have to incur merely to account for the facts of representation.

3. Epistemologically, the notion that we are in direct representational contact with abstracta or mental concreta throws a veil of appearances over the realm of external concreta, producing a corrosive scepticism about our knowledge thereof.

4. Phenomenologically, the entities we are aware of when we think of dragons and parrots present themselves to us, from the first-person perspective, as external concreta, not as mental concreta.

Kriegel (2007, 310-311).

\section{Aborted Modal Realism}

The problem of intentional inexistence is an inconsistent triad (Kriegel 2007, 309). To escape inconsistency we need to deny one of three propositions. The standard modal realist response amounts to denying the first proposition, (1). Kriegel quickly discusses modal realism in the following way, 'A more recent version of the view under consideration is that, when we seem to ourselves to think of dragons, we are thinking of possibilia' (Kriegel 2007, 310). ${ }^{7}$

\footnotetext{
${ }^{7}$ Kriegel does not mention by name anyone who actually holds this position. I know of no one who genuinely held this position in 2007. However, since the publishing of Kriegel's paper, a closer view has emerged. Now the closest position I know of is a view held by Bourne and Bourne (2016). However, their focus is on time in fiction rather than intentionality.
} 
Kriegel explains that against one ontology, ersatz modal realism, modal realism simply collapses into the abstract view. However, against a background of Lewis's modal realism, the suggestion is that we are thinking about non-mental concreta that do not exist in the actual world, they do exist else where in modal space simplicter (Lewis 1986, 3). ${ }^{8}$ By Kriegel's own admission this solution does avoid the problems associated with the abstracta and mental-concreta views (Kriegel 2007, 311). Despite it being successful in avoiding some objections, according to Kriegel, modal realism should be aborted on other grounds.

\subsection{Lewisian Modal Realism}

Lewisian modal realism is the view that there is a plenitude of other worlds where all manner of possibilities take place. It is the view that what could have been the way at this world is the way things are at some other world. Lewisian worlds are concrete wholes made of parts and individuals. These parts and individuals are referred to as posssibilia.

According to Kriegel, the Lewisian version of modal realism is not a viable option to solve the problem of intentional inexistence. Kriegel has two objections. The first is that modal realism exacerbates the ontological problem inasmuch as it commits us to the existence of non-actual concreta (Kriegel 2007, 331). Kriegel's second objection is that modal realism is inconsistent with the principle of representation. Kriegel defines this principle as follows.

...representation is always grounded in causal contact with the represented. On some views, causal contact is constitutive of representation. The requirement I have in mind is much weaker: that causal contact is a precondition for the possibility of representation (even if it is not constitutive of the representation itself). Since there is no trans-world causation, representation of non-actual concreta is inconsistent with this principle (Kriegel 2007, 311).

Kriegel argues these two reasons are good enough to abandon modal realist solutions to the problem of intentional inexistence. In the following section, I take each reason in turn and provide counter-arguments to both.

\section{Modal Realism Defended}

\subsection{Defence 1}

The first defence of modal realism I offer is against the challenge that its introduction 'exacerbates [2] the ontological problems, inasmuch as it commits us to the existence of non-actual concreta' (Kriegel 2007, 311). This is a methodological concern which comes about due to what you are willing to buy into and trade-off. It is clear that Kriegel is not willing to accept non-actual objects, and thus their advantages are not

\footnotetext{
${ }^{8}$ By 'simplicter' Lewis means that objects exist in the same way objects at actuality exist.
} 
available to him. If you are willing to accept non-actual objects then you gain access to philosophical benefits that come with them. One of which is a simple answer to the question 'What goes in the object box?' in the case of agents bearing intentional relations to a non-existent object. If you choose to decline non-actual objects then you must also abandon their benefits. This is a position Kriegel has put himself in, and it is not a deficiency of modal realism itself.

What is more, Kriegel opens himself up to criticism on the grounds of employing false parsimony. Kriegel's reaction to non-actual objects reveals he is sympathetic to economic theories and implies that he believes more economic theories are somehow superior to less economic theories. However, this is to misuse parsimony. Sober (1981: 1) states, 'The principle of parsimony counsels that we should hypothesise that an entity does not exist if its postulation is to no explanatory point' (Sober's italics). With Sober's formulation to hand, it is clear that non-actual concreta are no threat to the violation of the principle of parsimony. The presence of non-actual objects play an explanatory role and therefore we are on no grounds to cite them as "strange" metaphysical entities that ought to be avoided.

\subsection{Defence 2}

The second concern that Kriegel highlights is that modal realism fails to meet the principle of representation. This criticism targets a feature of Lewis's version of modal realism under which, there is no trans-world causation since Lewis's worlds are totally isolated from each other. ${ }^{9}$ Thus, modal realism set against this ontology cannot meet what is asked of it by the principle of representation. However, Lewis's modal realism is not the only brand of modal realism on offer. EMR is a brand of modal realism under which there are both possible and impossible worlds. Under EMR worlds are points in modal space. ${ }^{10}$ In EMR objects are not only temporally extended but they are also modally extended. ${ }^{11}$ To use the temporal analogue, we might say that I have past and future stages, likewise, we might also say I have possible and impossible stages. ${ }^{12}$ However, unlike Lewis's modal realism, in EMR there is only one universe in which all objects and their stages belong.

Another dissimilarity between Lewis's modal realism and EMR is that under EMR my modal stages are related in part-hood to my actual stage. Given this part-hood relation and the single universe, the possible and impossible stages of objects are not totally isolated as they would be if they belonged to different Lewisian worlds. The part-hood relation does not mean that there can be some kind of butterfly effect between modal parts. The actual parts of an object cannot change the way the possible or impossible parts of objects are, at least not in a chain-like way. Yagisawa

\footnotetext{
${ }^{9}$ Lewis believes his worlds are both spatiotemporally and causally isolated (Lewis 1986, p.70) and (Lewis 1986, 78).

${ }^{10}$ EMR was originally introduced in Yagisawa (1988) and developed in Yagisawa (2010).

${ }^{11}$ Yagisawa (2010, 44-45) plays up the temporal analogue between modal realism and eternalism, an analogue that Lewis plays down.

${ }^{12}$ Yagisawa, calls these modal stages 'world stages' (Yagisawa 2010).
} 
clarifies the relationship between possible worlds: 'I regard what Lewis calls "possible worlds" as modal parts of one and the same universe. The universe's modal parts are not possible worlds, but the universe itself as it is at possible worlds, its world-stages' (Yagisawa 2010, 44). He continues: 'my modal space (collection of all possible worlds I embrace and all objects existing at them) contains many concrete objects all of which are modal parts of one and the same universe' (Yagisawa $2010,44)$. The best way to understand the relationship between world-stages is to compare them to Lewisian worlds. For Lewis worlds are spatiotemporally unrelated by definition. However, this is not quite the case under EMR since 'The space and time of one world are the same space and time of many other worlds. Space and time permeate many different worlds. The space and time that exist at the actual world, however, do not exist at some remote possible worlds, being replaced by alien space and time, or no space or time at all (if that is possible)' (Yagisawa 2010, 45-46).

If we consider Jane as she is in a spatial region $r$ at a time $t$ at a world $w_{1}$, and John as he is in $r$ at a different world $w_{2}$. The proponent of EMR supplies two ways we could understand spatiotemporal relations:

1. The first way we could understand spatiotemporal relation is as 'Jane at $w_{1}$ is in $r$ at $t$, and so is John at $w_{2}$. They are in the same region of space at the same time. They are also in the same universe, albeit at different modal points. In that sense they are certainly spatiotemporally related.'

2. The second way is as a physical relation between Jane and John. 'Jane at $w_{1}$ could not reach out and touch John at $w_{2}$, or anyone or anything at $w_{2}$, no matter how fast or how far she travels through space and time at $w_{1}$ '.

Yagisawa (2010: 45-46).

In sum, the answer Yagisawa gives to the question as to whether possible worlds are spatiotemporally related is, yes. By this, he means that two or more worlds can have the same space-time. Objects at possible worlds can share the same spatial and temporal regions but differ in their modal location.

What remains is to question what is meant by 'causal contact'. If causal contact in the principle of representation comes down to spatiotemporal relations then Yagisawa provides two ways to interpret this. The first way that we could interpret causal contact is that causal contact amounts to the space-time being the same at different worlds. The second way we could interpret causal contact is in the physical sense in which Jane could reach out and touch John. Let us call them causal contact ${ }^{1}$ and causal contact ${ }^{2}$ respectively. If causal contact requires agents to be connected to the objects of our intentions in Yagisawa's second sense, - causal contact ${ }^{2}$ then the condition is absurd and should be rejected. There is no way that I could be causally connected in this way with many kinds of ordinary objects. The reason for this might come down to a number of factors, including practical possibility, physical possibility, or metaphysical possibility. For example, I can think about the centre of the earth without being causally connected ${ }^{2}$ to it. I can think of stars that are billions of light years away without being causally connected ${ }^{2}$ to them. And I can think 
of Sherlock Holmes without being causally connected ${ }^{2}$ to him either. ${ }^{13}$ If we take causal contact to mean causal contact ${ }^{2}$ then it reduces the objects of our intention to only those objects which are spatially accessible to us, which is absurd. However, if the requirement is set with Yagisawa's first sense in mind, — causal contact $^{1}$ then EMR meets this condition in virtue of some worlds and their objects being unified by spatiotemporal relatedness (Yagisawa 2010, 45). Under EMR at least some worlds are spatiotemporally related, the ones where the space and time are the same. If all that is required for causal contact is spatiotemporal relatedness then EMR can, at least in some cases, meet this minimal demand. However, an objector might say spatiotemporal relatedness in this sense does not seem to capture what is wanted from the principle of representation. The principle of representation seems to require direct causal contact between the representer and the represented. Modal realism is not out of the woods just yet. Our final option is to challenge the principle of representation.

\subsection{Defence 3}

My third and final defence of modal realism is to argue that the principle of representation is asking too much from any theory. It seems to be used as an ad hoc condition to rule out modal realism as a viable solution to the problem of intentional inexistence. The inclusion of the principle takes too much else with it, including Kriegel's own solution. The principle of representation states that causal contact is a precondition for the possibility of representation. However, we have already seen that there are plenty of objects that we are not in causal contact with which we can represent with ease, fictional characters and distant stars for example. It seems set against many ontologies, not just modal realism, this principle is troublesome. It precludes anyone with an anti-realist ontology of fictional characters from representing them. It also limits those with Meinongian ontologies in the same way. Realists are no better off. Unless the objects of our representations are located at actuality in the strict sense and even when this is the case, what it means to be in causal contact with an inexistent object located at actuality seems difficult to define if not impossible. Acceptance of the principle limits the scope of the relevant objects of our representation too much. Moreover, if we take this principle seriously not even Kriegel's own account survives, unless he thinks we are in causal contact with Bigfoots (Kriegel 2007, 314). The principle of representation says nothing about only applying to relational accounts of representation and thus it surely applies to Kriegel's non-relational account too.

\footnotetext{
${ }^{13} \mathrm{~A}$ critic of my position might insist that we could be causally connected ${ }^{2}$ to the centre of the earth via a chain of causal connections. And although we are not directly connected to the centre of the earth this chain of connections is sufficient to be causally connected ${ }^{2}$ to the centre of the earth. By way of response I say that there is no way there can be a complete chain like this which is causal connects ${ }^{2}$ to an agent to an object which we are not in direct acquaintance with. Causal connect ${ }^{2}$ requires a direct connection. This challenge admits we are not in direct acquaintance with the object and thus this isn't a case of causally connect $^{2}$. A chain of this kind would be one of causal connect ${ }^{1}$ which we know EMR can satisfy. Thank you to an anonymous reviewer for alerting me to this possible criticism.
} 


\section{Conclusion}

Modal realism can minimally meet the principle of representation in certain cases. Or we take the more sensible option and reject the principle of representation altogether. It is a restrictive principle that rules out too many instances of standard representational acts with no good reason and seems inadequate to deal with cases of intentional inexistence. I have shown that there is still hope for a modal realist answer to the problem of intentional inexistence by rejecting that a direct causal connection need hold between the agent and the object of representation. However, the debate doesn't end here. With the causal principle of representation gone what stands in its place? My suggestion is that what is required for representation is doxastic access to a state of affairs. The requirements for doxastic access are lower than epistemic or perceptual access. Doxastic access only needs an agent to be able to form beliefs about a state of affairs. I suggest something like the possible world box used in Nichols and Stich (2003) gives us doxastic access to possible worlds. The usefulness for such a mental device has already been suggested by Berto (2017). What is more, doxastic access to possible worlds has already been highlighted as a feature of modal realism by Lewis (1986: 27) so it looks like this suggestion would have some success and is to be explored in later work.

Open Access This article is distributed under the terms of the Creative Commons Attribution 4.0 International License (http://creativecommons.org/licenses/by/4.0/), which permits unrestricted use, distribution, and reproduction in any medium, provided you give appropriate credit to the original author(s) and the source, provide a link to the Creative Commons license, and indicate if changes were made.

\section{References}

Berto, F. (2017). Impossible worlds and the logic of imagination. Erkenntnis, 82(6), 1277-1297.

Berto, F. (2018). Aboutness in imagination. Philosophical Studies, 175(8), 1871-1886.

Bourne, C., \& Bourne, E.C. (2016). Time in Fiction. Oxford: Oxford University Press.

Brentano, F. (2012). Psychology from an Empirical Standpoint. Abingdon-on-Thames: Routledge.

Chisholm, R. (1957). Perceiving. Ithaca: Cornell University Press.

Crane, T. (2001). Elements of Mind. Oxford: Oxford University Press.

Crane, T. (2006). Brentano's concept of intentional inexistence. In The Austrian Contribution to Analytic Philosophy (pp. 28-43). Abingdon-on-Thames: Routledge.

Crane, T. (2013). The Objects of Thought. Oxford: Oxford University Press.

Dummett, M. (2014). Origins of Analytical Philosophy. London: A\&C Black.

Hawthorne, J., \& Manley, D. (2012). The reference book. Oxford University Press.

Kriegel, U. (2007). Intentional inexistence and phenomenal intentionality. Philosophical Perspectives, 21(1), 307-340.

Lewis, D. (1986). On the plurality of worlds. New Jersey: Wiley-Blackwell.

Mumford, S., \& Anjum, R.L. (2011). Getting causes from powers. Oxford: Oxford University Press.

Nichols, S., \& Stich, S.P. (2003). Mindreading: An Integrated Account of Pretence, Self-awareness and Understanding Other Minds. Oxford: Clarendon Press/Oxford University Press.

Priest, G. (1997). Sylvan's box: a short story and ten morals. Notre Dame Journal of Formal Logic, 38(4), $573-582$.

Priest, G. (1999). Perceiving contradictions. Australasian Journal of Philosophy, 77(4), 439-446.

Priest, G. (2014). One: Being an Investigation Into the Unity of Reality and of its Parts Including the Singular Object which is Nothingness. Oxford: Oxford University Press.

Priest, G. (2016). Towards Non-being. Oxford: Oxford University Press. 
Prior, A.N. (1971). Objects of Thought. Oxford: Oxford University Press.

Sober, E. (1981). The principle of parsimony. The British Journal for the Philosophy of Science, 32(2), $145-156$.

Yablo, S. (2014). Aboutness. Princeton: Princeton University Press.

Yagisawa, T. (1988). Beyond possible worlds. Philosophical Studies, 53(2), 175-204.

Yagisawa, T. (2010). Worlds and Individuals Possible and Otherwise. Oxford: Oxford University Press.

Yagisawa, T. (2014). Deflationary existence. Annals of the Japan Association for Philosophy of Science, $22,1-16$

Publisher's Note Springer Nature remains neutral with regard to jurisdictional claims in published maps and institutional affiliations. 